\title{
OPEN Effects of a bacteria-produced algicide on non-target marine invertebrate species
}

\author{
Victoria E. Simons, Kathryn J. Coyne, Mark E. Warner, Margaret M. Dolan \& \\ Jonathan H. Cohen $₫$
}

Harmful algal blooms (HABs) affect both freshwater and marine systems. Laboratory experiments suggest an exudate produced by the bacterium Shewanella sp. IRI-160 could be used to prevent or mitigate dinoflagellate blooms; however, effects on non-target organisms are unknown. The algicide (IRI-160AA) was tested on various ontogenetic stages of the copepod Acartia tonsa (nauplii and adult copepodites), the blue crab Callinectes sapidus (zoea larvae and megalopa postlarvae), and the eastern oyster Crassostrea virginica (pediveliger larvae and adults). Mortality experiments with $A$. tonsa revealed that the $24-\mathrm{h}$ LC50 was $13.4 \% \mathrm{v} / \mathrm{v}$ algicide for adult females and $5.96 \%$ for early-stage nauplii. For C. sapidus, the $24-\mathrm{h}$ LC50 for first-stage zoeae was $16.8 \%$; results were not significant for megalopae or oysters. Respiration rates for copepod nauplii increased in the $11 \%$ concentration, and in the $11 \%$ and $17 \%$ concentrations for crab zoeae; rates of later stages and oysters were unaffected. Activity level was affected for crab zoeae in the $1 \%, 11 \%$, and $17 \%$ treatments, and for oyster pediveliger larvae at the $17 \%$ level. Activity of later stages and of adult copepods was unaffected. Smaller, non-target biota with higher surface to volume could be negatively impacted from IRI160AA dosing, but overall the taxa and stages assayed were tolerant to the algicide at concentrations required for dinoflagellate mortality $(E C 50=\sim 1 \%)$.

Harmful algal blooms (HABs) are a world-wide phenomena that are increasing in number and intensity, leading to growing efforts to identify methods for prevention or mitigation of blooms ${ }^{1-5}$. With harmful algal blooms comes the bioavailability of harmful compounds these algae produce; in Delaware, USA, blooms of harmful algae including Karlodinium veneficum have been reported ${ }^{6}$, with $K$. veneficum producing karlotoxins responsible for hemolytic, cytotoxic, and ichthyotoxic effects ${ }^{7}$. These toxins create pores in cellular membranes that disrupt ion gradients, leading to lysis and ultimately fish kills ${ }^{8,9}$ and similarly negative effects on invertebrates ${ }^{10,11}$.

Natural compounds hold promise for combating HABs, provided that they minimally impact non-target organisms ${ }^{1,12}$. One potential approach to mitigate HABs is to apply naturally occurring species or the compounds they produce ${ }^{1}$. For example, Jeong et al..$^{13}$ demonstrated that compounds extracted from certain seaweeds had algicidal effects on various red tide microalgae. Similarly, there are a growing number of bacterial isolates that have negative impacts on certain algae, some of which are irreversible and lead to cellular lysis ${ }^{14-19}$. In addition, algicidal bacteria and their compounds may be applied to HAB management, but more testing is needed to ensure possible negative environmental effects are avoided ${ }^{20-22}$.

Shewanella sp. IRI-160 - a gammaproteobacteria isolated from Delaware waters -produces algicidal compounds. IRI-160 exudate (hereafter referred to as algicide, IRI-160AA, and IRI-160 algicide) negatively affected harmful dinoflagellates while exhibiting little to no negative effects on other algae; it appears to trigger cell cycle arrest and programmed cell death (PCD) in harmful dinoflagellates ${ }^{23-27}$. Thus, there is an interest in determining if IRI-160AA may mitigate blooms of harmful dinoflagellates in coastal waters. While the algicidal compound(s) have yet to be fully isolated ${ }^{28}$, an alternative approach is to determine how the whole bacterial exudate may affect non-target species ${ }^{23-27}$.

Any compound used to control or mitigate HABs may have unintended effects on higher trophic levels. Similar to other natural and anthropogenic stressors (e.g., temperature, salinity, oil, dispersant, etc.), these are manifested through either mortality ${ }^{29-31}$ or sublethal effects ${ }^{32-36}$. Lethal and sublethal assays with IRI-160AA (or a similar compound) and key metazoan taxa should help determine if food webs are altered by widescale application. A similar approach with IRI-160AA was recently tested at lower trophic levels: after exposing a planktonic community to the algicide, Tilney et al. ${ }^{26}$ noted an increase in heterotrophic protists and a bactivorous 


\begin{tabular}{|l|l|l|l|l|l|l|}
\hline & \multicolumn{2}{|l}{ A. tonsa } & \multicolumn{2}{l|}{ C. sapidus } & \multicolumn{2}{l|}{ cirginica } \\
\cline { 2 - 7 } & Nauplius & Adult female & Zoeae & Megalopae & Pediveliger & Adult \\
\hline 48-h LC50 & 1.09 & N. S.. & - & N. S. & 10.9 & - \\
\hline Lower CI & 0.497 & N. S. & - & N. S. & 8.56 & - \\
\hline Upper CI & 1.78 & N. S. & - & N. S. & 13.2 & - \\
\hline$p$-value & 0.027 & N. S. & - & N. S. & $<0.001$ & - \\
\hline 24-h LC50 & 5.96 & 12.2 & 16.8 & N. S. & N. S. & N. S. \\
\hline Lower CI & 4.54 & 10.6 & 13.5 & N. S. & N. S. & N. S. \\
\hline Upper CI & 7.29 & 13.9 & 22.6 & N. S. & N. S. & N. S. \\
\hline$p$-value & $<0.001$ & $<0.001$ & $<0.001$ & N. S. & N. S. & N. S. \\
\hline 18-h LC50 & 8.62 & 14 & 26.2 & N. S. & N. S. & N. S. \\
\hline Lower CI & 7.26 & 12.2 & 19.3 & N. S. & N. S. & N. S. \\
\hline Upper CI & 9.85 & 16 & 49.4 & N. S. & N. S. & N. S. \\
\hline$p$-value & $<0.001$ & $<0.001$ & $<0.001$ & N. S. & N. S. & N. S. \\
\hline 12-h LC50 & 10.3 & 18 & N. S. & N. S. & N. S. & N. S. \\
\hline Lower CI & 8.83 & 16.2 & N. S. & N. S. & N. S. & N. S. \\
\hline Upper CI & 11.6 & 20.2 & N. S. & N. S. & N. S. & N. S. \\
\hline$p$-value & $<0.001$ & $<0.001$ & N. S. & N. S. & N. S. & N. S. \\
\hline 6-h LC50 & N. S. & 29.4 & N. S. & N. S. & N. S. & N. S. \\
\hline Lower CI & N. S. & 25.6 & N. S. & N. S. & N. S. & N. S. \\
\hline Upper CI & N. S. & 36.2 & N. S. & N. S. & N. S. & N. S. \\
\hline$p$-value & N. S. & $<0.001$ & N. S. & N. S. & N. S. & N. S. \\
\hline
\end{tabular}

Table 1. LC50s (\% v/v) for different organisms at different time points, along with their associated confidence intervals as determined from Probit analysis. (N. S. = Not significant, $p>0.05$; “-“ Not tested).

chrysophyte. After repeated IRI-160AA dosing, Grasso ${ }^{27}$ also noted a decline in dinoflagellates, while total algal biomass (recorded by fluorescence) was unchanged, thereby suggesting a community shift in phytoplankton that filled the void left by the dinoflagellates. Further, while some ciliate species also increased, community grazing rates either remained the same or increased after algicide application.

Beyond the microbial and microzooplankton communities, the effects of IRI-160AA on metazoans are unknown. Here, we tested IRI-160AA with three metazoan taxa. Acartia tonsa is a calanoid copepod that reaches lengths from 1 to $1.5 \mathrm{~mm}^{37}$ and is among the most abundant mesozooplankters in Mid-Atlantic estuaries, where they are critical phytoplankton grazers and food for larval and juvenile fish ${ }^{38-40}$. The blue crab, Callinectes sapidus, is a brachyuran crab found in Mid-Atlantic estuaries during its juvenile and adult life, while spending its larval period on the inner continental shelf ${ }^{38,41}$. This crab constitutes a large fishery along the United States Atlantic and Gulf coasts, making it both economically and ecologically important ${ }^{41}$. The eastern oyster, Crassostrea virginica, is a bivalve mollusk and an important Mid-Atlantic fishery, in addition to forming ecologically important oyster reefs $^{42}$. C. virginica filter large quantities of sea water, and their larvae have low prey selectivity across different phytoplankton species ${ }^{38}$.

We established lethal algicide levels of IRI-160AA with these three common estuarine taxa, as well as sublethal algicidal effects through respiration and behavioral assays conducted in both light and dark to account for diel periodicity in their physiology and behavior.

\section{Results}

Lethal effects. Species varied in their time-dependent mortality with algicide exposure (Tables 1,2$)$. Acartia tonsa nauplii had a $24-\mathrm{h}$ LC50 of $5.96 \% \mathrm{v} / \mathrm{v}(p<0.001$, CI 4.54-7.29\%) (Fig. 1a). For A. tonsa adult females, the LC50 was approximately two-fold higher at 12.2\% ( $p<0.001,95 \%$ CI 10.6-13.9\%) (Fig. 1b).

Callinectes sapidus zoeae had a 24-h LC50 of approximately $16.8 \% \mathrm{v} / \mathrm{v}(p<0.001$, CI 13.5-22.6\%) (Fig. 1c). Megalopae proved far more resistant to the algicide: no treatments had greater than $10 \%$ mortality, even after $48 \mathrm{~h}$ of exposure, thus we could not calculate an LC50 (Fig. 1d).

Crassostrea virginica pediveligers had less than $20 \%$ mortality through the 24 -h time point. By $48 \mathrm{~h}$, greater mortality allowed calculation of an LC50 of $10.9 \% \mathrm{v} / \mathrm{v}(p<0.001$, CI 8.56-13.2\%) (Fig. 1e). For adult oysters, no individuals died during the experiments at any concentration or time point tested (Fig. 1f).

Copepod sub-lethality. Activity. Total activity levels were unaffected in adult female A. tonsa exposed to all concentrations of algicide tested (one-way ANOVA on ranks, $p=0.952$ ).

When activity was binned at 30 min intervals and separated into an initial light phase (L1), a dark phase (D), and a second light phase (L2) in order to account for diel activity rhythms, there still was no significant difference among treatments (one-way RMANOVA, $p=0.727$ ). However, there was an overall difference between the initial light phase (L1) and final light phase (L2) ( $p=0.039$; Tukey post hoc, $p=0.041)$, with activity lower in the L2 phase. There was no interaction between treatment and time (Tukey post-hoc, $p=0.164$ ). 


\begin{tabular}{|l|l|l|l|l|l|l|}
\hline \multirow{2}{*}{$\begin{array}{l}\text { A. } \text { tonsa } \\
{[\text { Algicide] }}\end{array}$} & Nauplius & Adult Female & Zoeae & Megalopae & Pediveliger & Adult \\
\hline $1 \%$ & N. S. & N. S. & N. S. & N. S. & N. S. & N. S. \\
\hline $5 \%$ & $* *$ & N. S. & N. S. & N. S. & N. S. & N. S. \\
\hline $10 \%$ & $* * *$ & N. S. & N. S. & N. S. & $*$ & N. S. \\
\hline $13.5 \%$ & $* * *$ & N. S. & N. S. & $* * *$ & N. S. \\
\hline $15 \%$ & - & $*$ & N. S. & - & - & - \\
\hline $18 \%$ & $* * *$ & $* * *$ & N. S. & $* * *$ & N. S. \\
\hline $24 \%$ & $* * *$ & $* * *$ & $* * *$ & N. S. & $* * *$ & N. S. \\
\hline $30 \%$ & $* * *$ & $* * *$ & - & - & - & - \\
\hline $40 \%$ & - & $* * *$ & - & - & - & - \\
\hline
\end{tabular}

Table 2. P-values from Gehan-Breslow survival analysis $(p<0.001$ for all except $C$. sapidus megalopae and C. virginica adults, where $p>0.05$ ) post-hoc analysis (Holm-Sidak). The left most column is concentration of algicide $(\% \mathrm{v} / \mathrm{v}) .\left(-=\right.$ Not tested; N. S. $=$ Not significant, $\left.p>0.05 ;{ }^{*}=p<0.05 ;{ }^{* *}=p<0.01,{ }^{* *}=p<0.001\right)$.
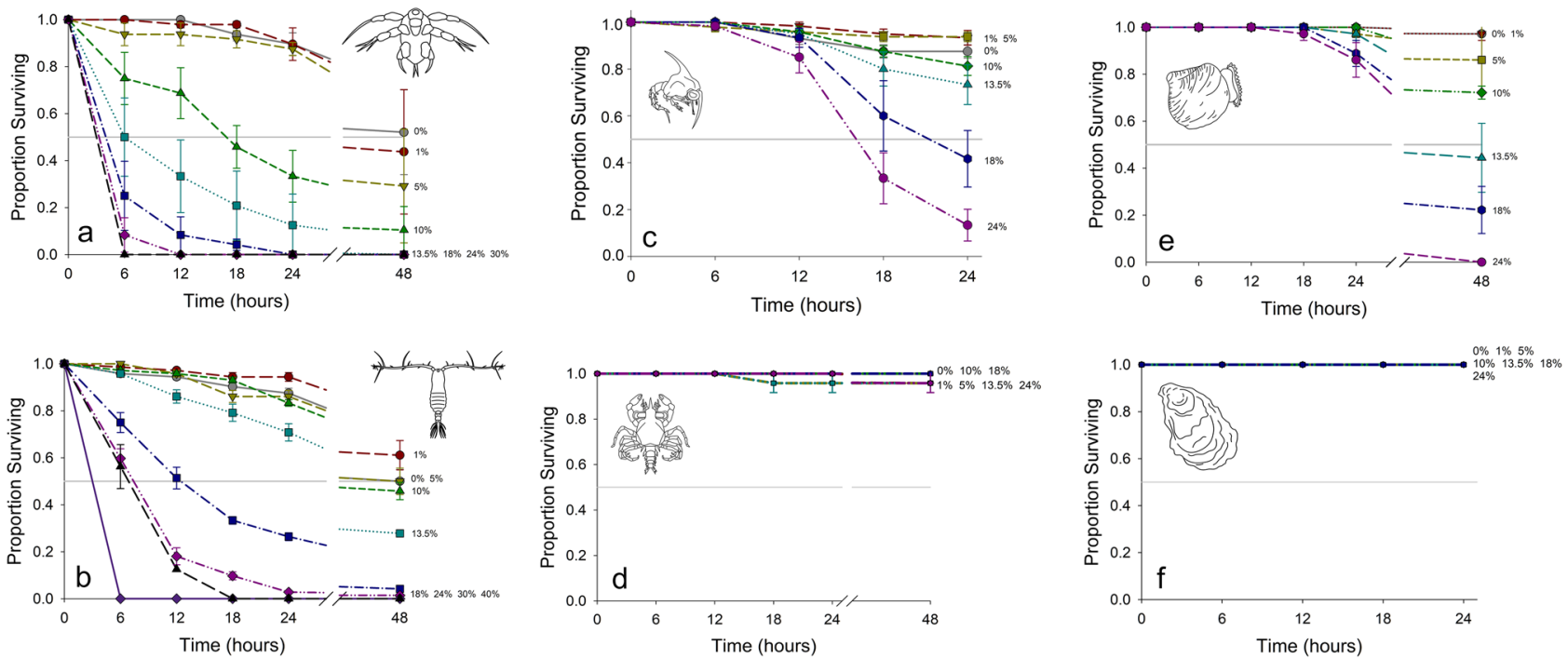

Figure 1. Survival of invertebrate taxa over time in different concentrations of IRI-160AA; the grey horizontal line marks 50\% survival. (a) A. tonsa nauplii, (b) A. tonsa adult females, (c) C. sapidus zoeae, (d) C. sapidus megalopae, (e) C. virginica pediveligers, (f) C. virginica adults. See Table 1 for LC50s.

Analyzing the proportion of dead individuals at the end of the activity experiments with $A$. tons $a$ adult females (i.e., after $24 \mathrm{~h}$ in clean water following a prior 24-h algicide exposure) revealed that only the $17 \%$ concentration had higher mortality relative to the $0 \%$ control (one-way ANOVA on Ranks, $p=0.012$; Dunn's test post-hoc, $p=0.040)$ (Fig. 2a).

Respiration. Nauplii had higher respiration at the $11 \%$ concentration relative to the $0 \%$ control animals (oneway ANOVA on Ranks, $p=0.039$; Dunn's Method post hoc, $p=0.012$ ), but not at any other concentration (Fig. 3a). Respiration rates of adult female $A$. tonsa were unaffected by 24 -h algicide exposure (one-way ANOVA on Ranks, $p=0.115$ ) (Fig. 3b).

Crab sub-lethality. Activity. Crab zoeae activity levels differed among treatments (one-way ANOVA, $p=0.020$ ). While average values for all treatments exceeded the $0 \%$ controls, only at $11 \%$ and $17 \%$ algicide were these differences significant (pairwise Holm-Sidak post hoc, $p=0.044, p=0.049$, respectively) (Fig. $4 \mathrm{a}$ ). When analyzed by light:dark phase (Fig. $4 \mathrm{c}$ ), there was higher activity in the $1 \%, 11 \%$, and $17 \%$ treatments versus the control during the L1 phase only for the zoeae (one-way RMANOVA, $p<0.001$ for interaction; Tukey post hoc, $p=0.02, p<0.001, p=0.013$ respectively). There were no other differences between any of the treatments. Differences disappeared during the dark phase (D) ( $p=0.994$ for $1 \%, 0.429$ for $11 \%$, and 0.062 for $17 \%)$ and during L2 ( $p=0.79$ for $1 \%, 0.986$ for $11 \%$, and 0.959 for $17 \%$ ). Also of note was a difference between the two light phases and between the L1 and D phases for all concentrations, and only a difference between the D and L2 phases for the $11 \%$ and $17 \%$ treatments ( $p<0.001$ for all) (Fig. 4 c). Overall, activity decreased with time. There were no significant differences in the proportion of dead individuals at the end of the LAM experiments for $C$. sapidus zoeae for any concentration ( $p=0.058)$ (Fig. 2b). 

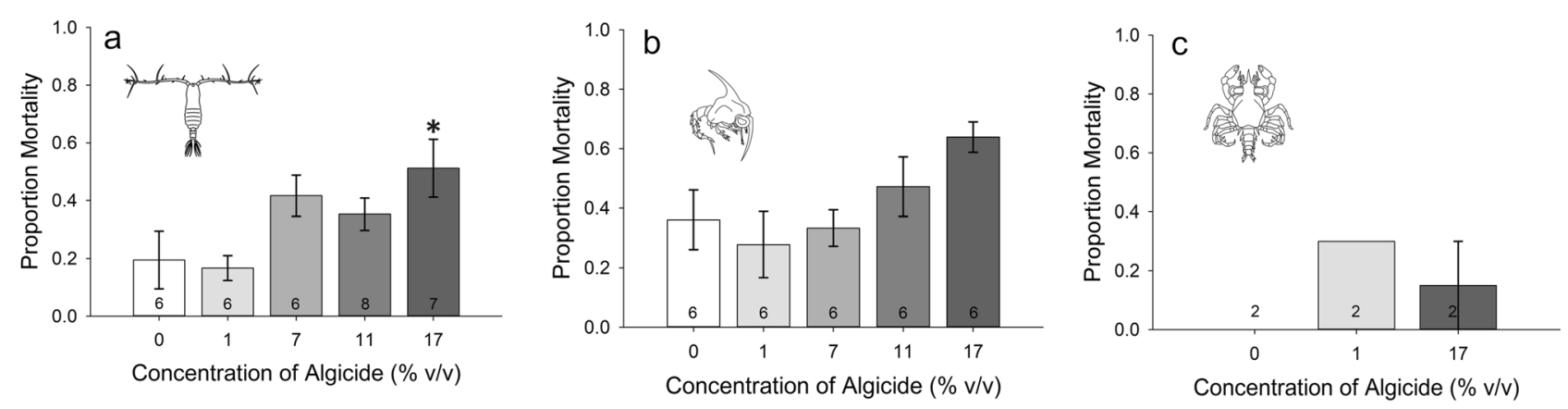

Figure 2. Mortality of invertebrate taxa during LAM experiments; mortality was assessed after $24 \mathrm{~h}$ in clean water following a prior 24-h algicide exposure. (a) Mortality of $A$. tonsa adult females. Only the $17 \%$ concentration had statistically higher mortality than the control (one-way ANOVA on Ranks, $p=0.012$; Dunn's test post-hoc, $p=0.040$ ). Mortality of $C$. sapidus zoeae (b) and megalopae (c). Neither crab life stage had statistically significant mortality compared to the control for any algicide concentration tested $(p>0.05)$. $\left({ }^{*} p<0.05\right)$.

(2)

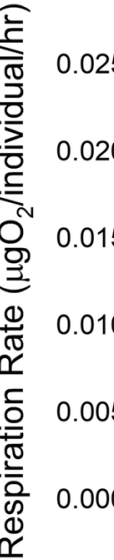

a

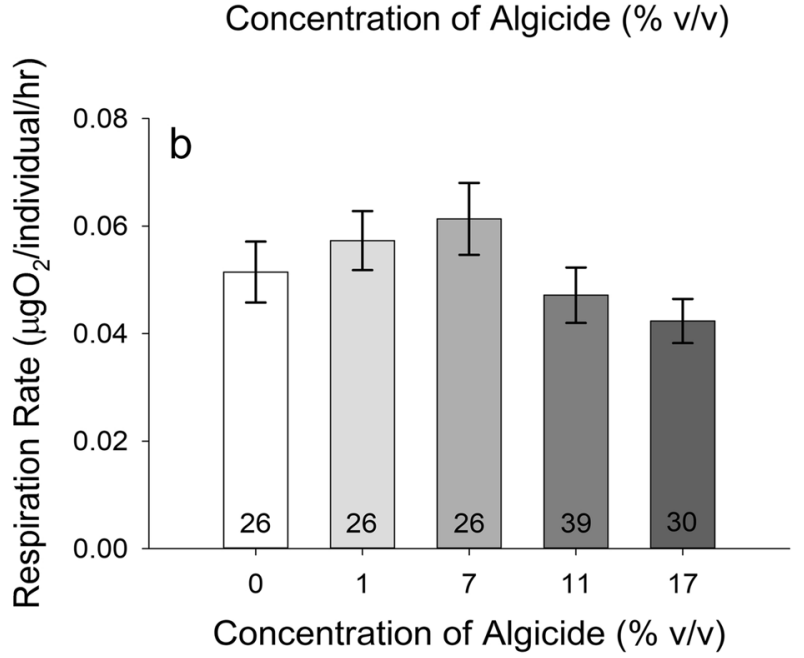

Figure 3. Respiration rates of Acartia tonsa; numbers on the bars represent sample size. (a) Respiration rate of nauplii $A$. tons $a$ as a function of algicide concentration. There was a statistically significant difference between the rates of the $11 \%$ animals and the $0 \%$ control animals (one-way ANOVA on Ranks, $p=0.039$; Dunn's Method post hoc, $p=0.012$ ). (b) Respiration rate of adult female $A$. tonsa as a function of algicide concentration. $\left({ }^{*} p<0.05\right)$. 

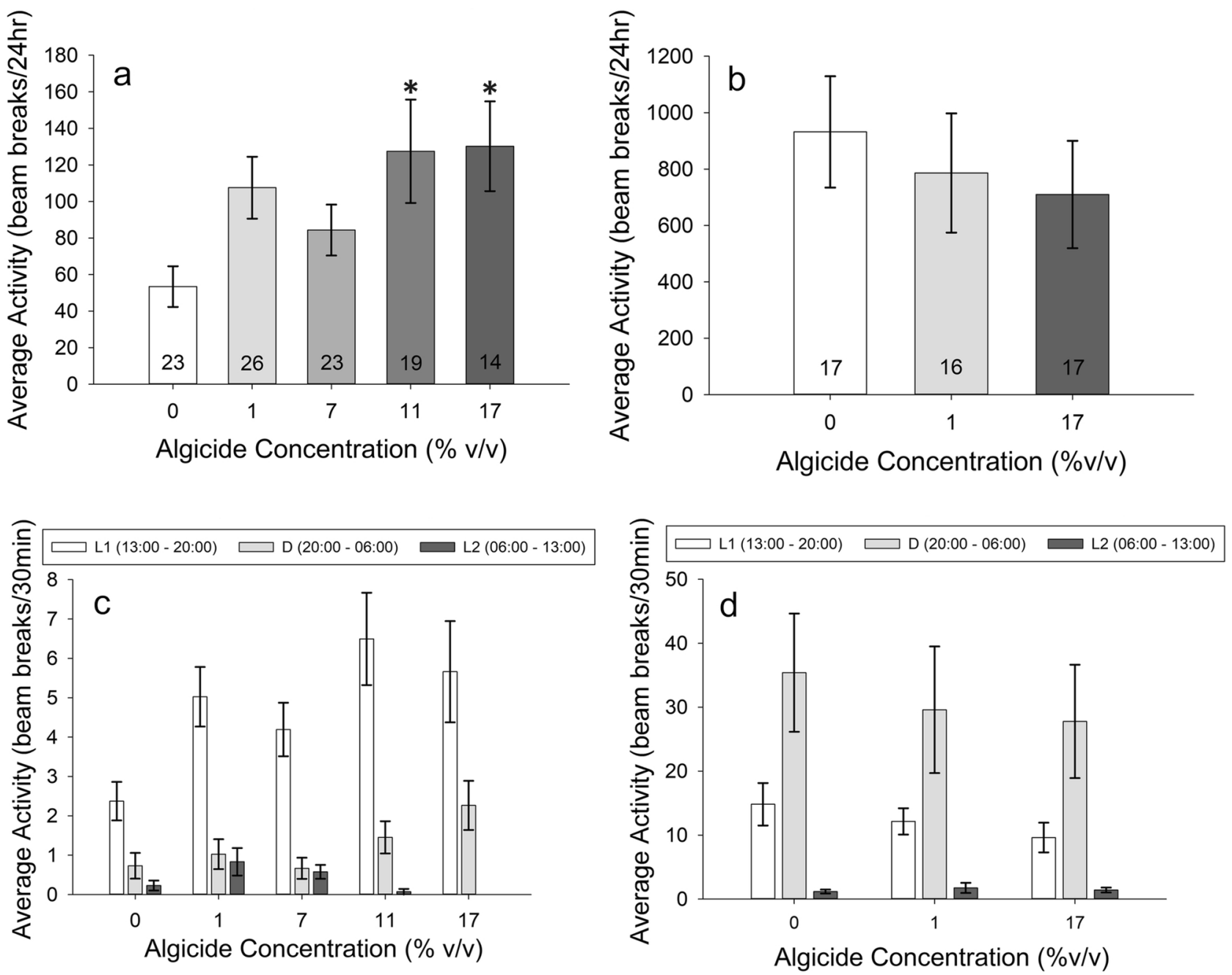

Figure 4. Activity levels of Callinectes sapidus; numbers on the bars represent sample size. Row 1: Activity level of C. sapidus zoeae (a) and megalopae (b) as a function of algicide concentration over a 24-h period. Animals were first pre-exposed to the listed concentrations of algicide for $24 \mathrm{~h}$, then placed into tubes of algicide-free water for activity measurements over the subsequent $24 \mathrm{~h}$. Row 2: Data from (a) and (b) broken down into activity per $30 \mathrm{~min}$ and separated by time of day for zoeae $(\mathbf{c})$ and megalopae $(\mathbf{d})$. Notice the scale differences among the graphs. $\left({ }^{*} p<0.05\right)$.

There was no significant difference in activity among treatments for megalopae (one-way ANOVA on Ranks, $p=0.737$ ) (Fig. 4b). There was also no significant difference among treatments for the megalopae when analyzed by light phase (one-way RMANOVA, $p=0.694$ ) (Fig. $4 \mathrm{~d}$ ). However, there was an overall difference among the three light phases ( $p<0.001$; Tukey post hoc, $p<0.001$ for all three comparisons). Activity was highest in the D phase, followed by the L1 phase, and was lowest in the L2 phase. There was no interaction between treatment and time for the megalopae $(p=0.773)$ (Fig. $4 \mathrm{~d})$. There was no difference among treatments for the proportion of individuals dead at the end of the activity experiments for megalopae $(p=0.4)$ (Fig. $2 c)$.

Respiration. Crab zoeae had higher respiration rates at the $11 \%$ and $17 \%$ algicide concentrations relative to the $0 \%$ control, but not at lower concentrations (one-way ANOVA on Ranks, $p<0.001$; Dunn's Method post hoc, $p<0.001$ for $11 \%$ and $p=0.007$ for $17 \%$ ) (Fig. 5a). Megalopae respiration rate was unaffected by algicide at either concentration tested (1\% and 17\%; one-way ANOVA on Ranks, $p=0.396$ ) (Fig. 5b).

Metamorphosis. Time to metamorphosis (TTM) of megalopae to the first juvenile crab stage was unaffected by 24 -h algicide exposure at $0 \%, 1 \%$, and $17 \%$ concentrations (Kaplan-Meier Survival Analysis; Gehan-Breslow, $p=0.564$ ) (Supplementary Fig. S1). The median TTM for all three concentrations was $72 \mathrm{~h}$.

Abdomen pumping and grooming. We examined both pumping and grooming of the egg mass in ovigerous female $C$. sapidus when exposed to homogenized eggs (which provides a natural cue eliciting these behaviors) with and without algicide. Pumping and grooming did not differ with algicide exposure ( $\chi^{2}$ test, pumping, 

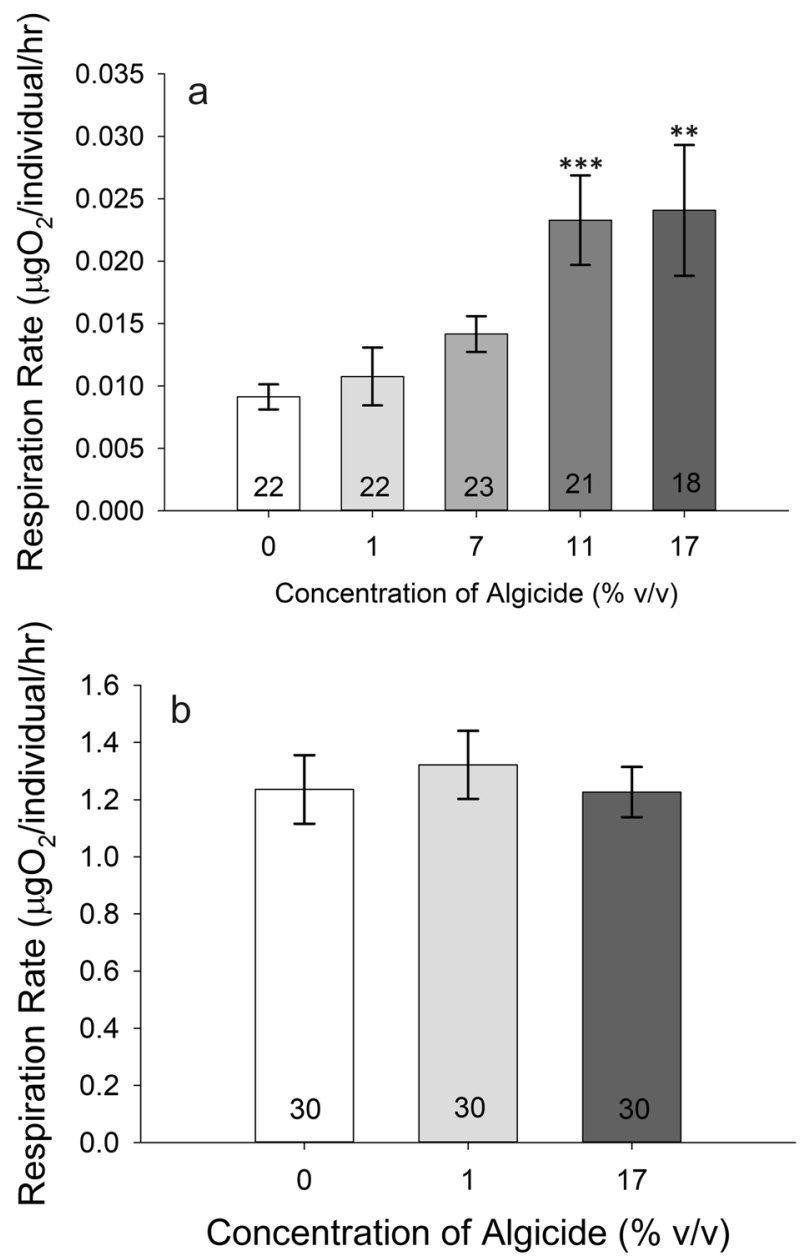

Figure 5. Respiration rates of Callinectes sapidus; numbers on the bars represent sample size. (a) Respiration rate of $C$. sapidus zoeae as a function of algicide concentration. Asterisks mark rates for algicide concentrations that are significantly different from the $0 \%$ control animals. (b) Respiration rate of C. sapidus megalopae as a function of algicide concentration. $\left({ }^{\star *} p<0.01 ;{ }^{* * *}=p<0.001\right)$.

$p=0.29$; grooming, $p=0.441$ ) (Supplementary Fig. S2). For the number of pumps ( $\mathrm{n}=9 \mathrm{crabs})$ and time spent grooming $(n=12$ crabs), there were no significant differences between any algicide treatment and the saltwater with homogenized eggs $(\mathrm{SW}+\mathrm{HE})$ control $(p>0.05)$ (Supplementary Fig. S2).

Oyster sub-lethality. Swimming activity. C. virginica pediveliger swimming activity dropped significantly at the $17 \%$ concentration relative to the $0 \%$ control animals, but not at the $1 \%$ concentration (one-way ANOVA on Ranks, $p<0.001$ ) (Fig. 6a).

When analyzed by light:dark phase, there was an interaction between light:dark phase and treatment (oneway RMANOVA, $p<0.001$ ) (Fig. 6b). Within the L1 phase, swimming activity was reduced in the $17 \%$ treatment relative to $0 \%$ controls (Tukey post hoc, $p<0.001$ ), but this difference disappeared in the dark $(p=0.681)$ and L2 $(p=1)$ phases. There was a significant difference between L1 and L2 and between L1 and D for both the $0 \%$ and the $1 \%$ algicide treatment $(p<0.001$ for all), but not for the $17 \%(p=0.913)$ (Fig. 6b). Overall, C. virginica pediveliger activity decreased with time.

We assessed additional oyster pediveliger activity during the mortality assay (i.e., while still exposed to algicide, and in contrast to locomotor activity monitor [LAM] experiments conducted in clean water after algicide exposures). For this assessment (which scored animals in the plates as exhibiting High, Medium, and Low activity at 24 and $48 \mathrm{~h}$; see Methods for details), there was a significant difference among algicide treatments at both the 24 - and 48 -h time points ( $\chi^{2}$ test, $p<0.001$ for each time point) (Fig. $\left.7 \mathrm{a}, \mathrm{b}\right)$. There was no significant difference among treatments in the same activity assessment at the end of the LAM experiment, $\left(\chi^{2}\right.$ test, $\left.p=0.401\right)$ (Fig. $\left.7 \mathrm{c}\right)$. When activity was binned as either active (swimming, velum extended) or inactive (sitting on the bottom, velum retracted), both the 24 - and 48 -h assessments were significantly different ( $\chi^{2}$ test, $p<0.001$ for $24 \mathrm{~h}$ and $p=0.002$ for $48 \mathrm{~h}$ ), while activity among treatments at the end of the LAM experiments were indistinguishable $(p=0.646)$. To determine which treatments were different from the controls in 24- and 48-h assays, multiple pairwise Fisher Exact Tests were run to compare each treatment to the $0 \%$ for both time points. At 24 -h, the $10 \%, 13.5 \%, 18 \%$, and $24 \%$ were all different from the control $(p<0.001$ for all). At 48 -h, the $10 \%$ and $13.5 \%$ were both different 

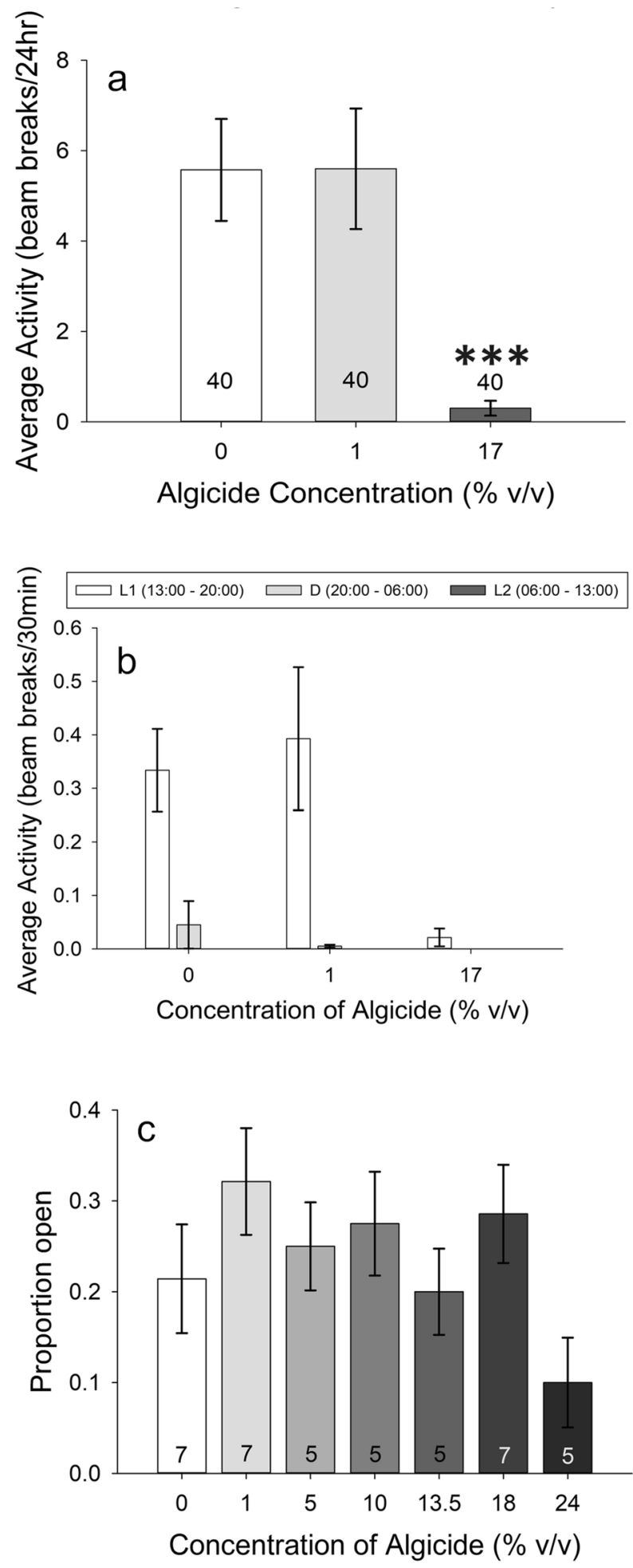

Figure 6. Activity levels of Crassostrea virginica; numbers on the bars represent sample size. (a) Activity level of $C$. virginica larvae as a function of algicide concentration over a 24-h period. Animals were first pre-exposed to the listed concentrations of algicide for $24 \mathrm{~h}$, then placed into tubes of algicide-free water for activity measurements over the subsequent $24 \mathrm{~h}$. (b) Data from (a) broken down into activity per 30 min and separated by time of day. (c) Adult C. virginica activity, given as proportion of individuals open. Animals were assessed in containers in pairs, creating a set of containers where the proportion open was either $0,0.5$, or 1 . These were checked at 4 time points and scored, data were averaged across time points to calculate an average proportion open for the container, then containers were averaged and plotted ( $\mathrm{n}$ values are given on each bar). $\left({ }^{* *} p<0.001\right)$. 

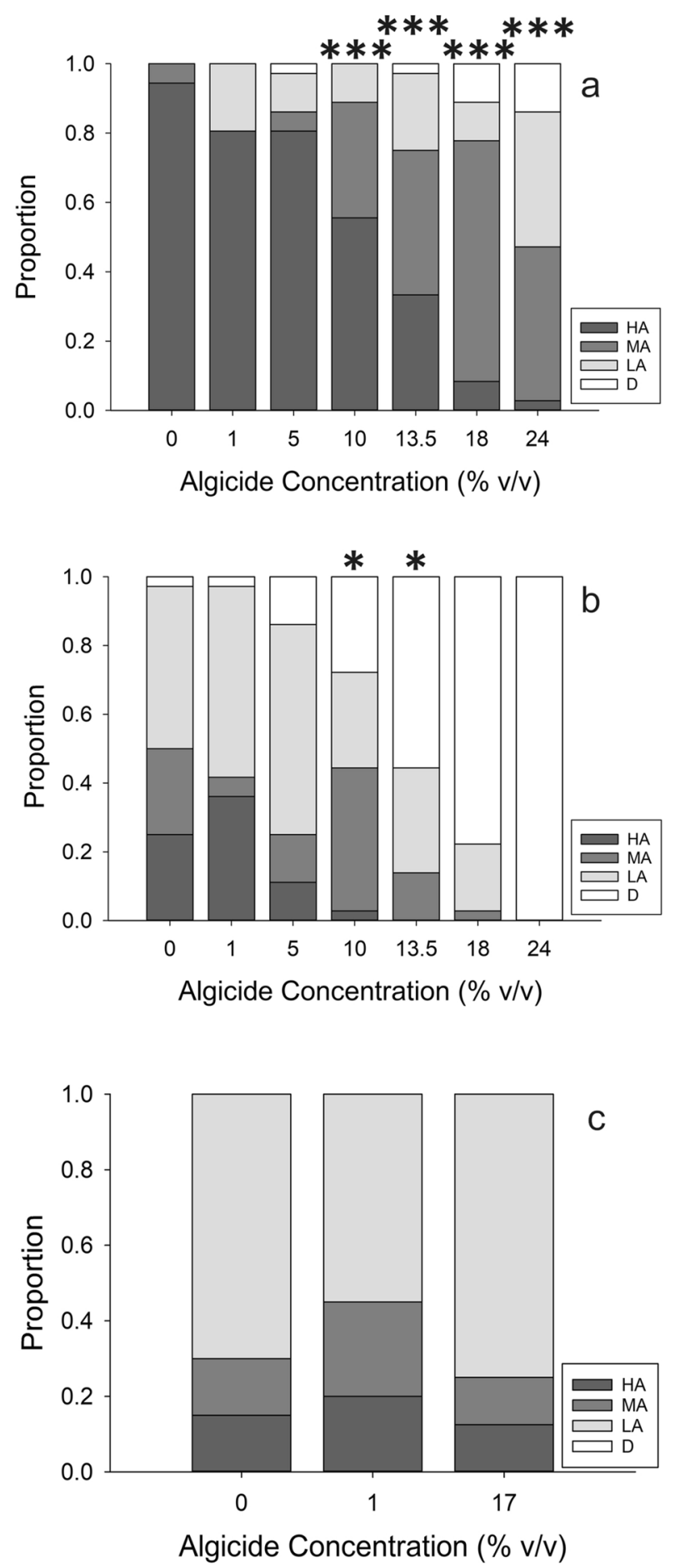

Figure 7. Activity of $C$. virginica larvae during the mortality experiments. Activity was scored at the beginning of the experiment (where all animals were scored High Activity), then at 24 (a) and 48 (b) hours. The 18\% and $24 \%$ concentrations were unable to be tested at 48 -h due to high mortality. Concentrations $10 \%$ and higher lead to changes in activity. Activity from the end of the LAM experiments is given in plot (c). There were no differences in activity at the end of the LAMs. $\left({ }^{*} p<0.05 ;{ }^{* *} p<0.001\right)$.

from the control ( $p=0.034$ and 0.043 ); the 18 and $24 \%$ were not compared due to high mortality. Overall, there was a trend of fewer animals marked as High activity with time, and with increasing concentration of IRI-160AA.

For adult $C$. virginica, there was no difference in the proportion of individuals with open shell valves based on treatment, time, or their interaction ( $p=0.582$ for treatment, 0.160 for time, and 0.492 for treatment $x$ time) (Fig. 6c). However, in the $24 \%$ treatment at both the 18 - and 24 -h time points, no individual had opened shell valves, which was not seen in any other concentration, including controls. 


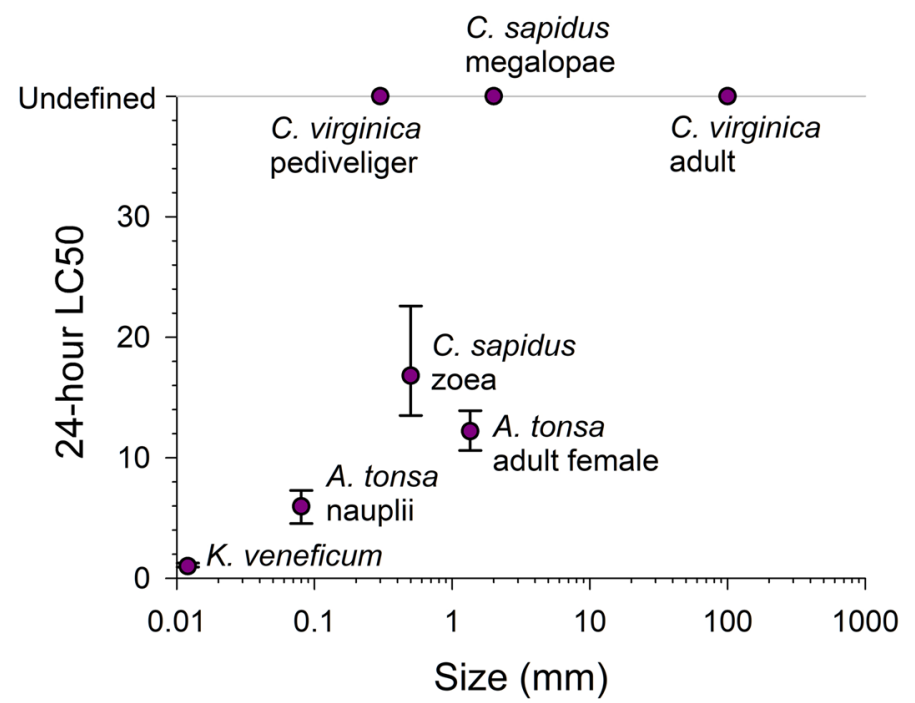

Figure 8. Size and 24-h LC50 for various animal species, as well as the EC50 for the harmful dinoflagellate Karlodinium veneficum. Error bars are 95\% CIs for LC50s. The grey line at the top is used to plot animals where a 24-h LC50 was not calculated. As size increases, generally so does LC50.

Respiration. Crassostrea virginica pediveliger respiration rates did not differ among the algicide concentrations (one-way ANOVA on Ranks, $p=0.093$ ). Mean respiration rates were $0.0072 \mu \mathrm{gO}^{2} /$ individual/hour for controls, $0.0066 \mu \mathrm{gO}^{2} /$ individual/hour for the $1 \%$ treatment, and $0.0046 \mu \mathrm{gO}^{2} /$ individual/hour for the $17 \%$ treatment.

Feeding. Clearance rates (CR) of adult C. virginica were similar across the different strains (wild-type and hatchery) and algicide concentrations (three-way ANOVA, $p>0.05$ ). There was a difference in CR based on exposure time (initial 6-h period, 0-6, versus second 6-h period, 6-12), independent of other factors (three-way ANOVA, $p<0.001$ ). CR in the 0-6 interval were higher than rates in the 6-12 interval (Supplementary Fig. S3).

\section{Discussion}

IRI-160AA is being investigated as an algicide for controlling and mitigating regularly occurring harmful dinoflagellate blooms in coastal ecosystems. Here, we evaluated its effects on non-target invertebrates. All taxa assayed had LC50s above the effective algicide concentration needed for controlling dinoflagellate growth (EC50 $\approx 1 \%$ $\mathrm{v} / \mathrm{v}$. $)^{27}$. For most taxa tested, the LC50 was a factor of 10 or greater above the dinoflagellate EC50. The most sensitive species/stage tested was A. tonsa copepod nauplii, with an LC50 fivefold higher than the dinoflagellate EC50. Importantly, the $1 \%$ treatments had very high survival at $24 \mathrm{~h}$ for all taxa tested - showing greater than $85 \%$ survival - and were not significantly different from the control.

For our mortality assays in general, the smaller, earlier life stages were more sensitive to the algicide than the larger, later life stages (Fig. 8). Similar effects of stage/size, or perhaps more directly surface area to volume ${ }^{43}$, have been reported for invertebrate mortality and sub-lethality in response to other contaminants such as pesticides ${ }^{44}$, dispersants ${ }^{33}$, and certain metals ${ }^{45}$. Given their ability to control tissue exposure by closing their shells, adult and larval oysters are unique among the taxa we tested. Such behavior helps explain why oyster pediveligers, despite being young and small, were more resistant to the algicide at 24-h compared to larger, older organisms like adult copepods. A similar point was reported by Tilney et al. ${ }^{26}$, where dinoflagellates with greater membrane exposure (e.g., athecate dinoflagellates) were more sensitive to IRI-160AA.

Beyond mortality, stressors can both positively and negatively affect invertebrate activity and physiology. Cohen et al. ${ }^{33}$ noted copepod swimming was negatively affected by both dispersed and undispersed crude oil. Porter and Brietburg ${ }^{34}$ recorded how Eastern oyster behavior changed in response to diel-cycling hypoxia; specifically, under severe hypoxic conditions the animals closed their shells, and reopened once waters became normoxic, indicating that these animals respond to environmental stressors with effective coping mechanisms. Forward et al. ${ }^{35}$ documented how environmental factors like humic acids and ammonia from estuaries help trigger or hinder blue crab molting from megalopae to first crabs, indicating the importance of environmental factors to their life history.

In the present study, mortality results suggested copepods are more vulnerable to algicide than are crab zoeae and oyster pediveligers. However, we observed greater sub-lethal effects in crab zoeae and oyster pediveligers than in copepods. Adult female copepods showed no signs of sub-lethal effects (activity or respiration) at any of the algicide concentrations. Copepod nauplii were not assayed for activity level due to their small size; however, their respiration rate was elevated in the $11 \%$ treatment. This concentration is above their calculated $\sim 6 \%$ LC50. Accordingly, for individuals that manage to survive initial exposure at the higher dosing concentrations that would be required in a field setting, effects after 24-h of algicide exposure may persist in clean conditions. Sublethal effects were more pronounced in both crab zoeae and oyster pediveligers, but again these were mostly 
limited to higher algicide concentrations that would more likely occur over limited areas during initial algicide dosing of a bloom.

Irrespective of time of day and tide, first-stage blue crab zoea larvae normally swim in order to remain in surface waters and move from estuaries to the coastal ocean ${ }^{46}$, thus no effect of time of day was expected. When activity was split by light phase, increased activity due to the algicide was limited to the first light phase; there was no difference in any treatment compared to the control during the dark phase and second light phase. Additionally, respiration rate did not increase in the $1 \%$ concentration, while activity and respiration rates were elevated in the $11 \%$ and $17 \%$ concentrations, suggesting that elevated activity was coupled with higher metabolic rates at these higher concentrations. Unlike zoeae, there were no sublethal effects in postalarval megalopae with algicide exposure. Interestingly, Forward et al. ${ }^{35}$ documented inhibited TTM with ammonium concentrations $\geq 25 \mu \mathrm{M}$, and IRI-160AA contains ammonium $>60 \mu \mathrm{M}$ (unpublished data). However, Forward et al. ${ }^{35}$ constantly exposed animals to ammonium, while our results are from animals exposed to algicide for $24 \mathrm{~h}$ and then assessed in clean sea water.

In the first light phase, oyster pediveliger larvae activity strongly decreased in the 17\% LAM treatment, and similar to the crab zoea larvae, this response disappeared in the dark phase and second light phase; this was measured in clean water after algicide exposure. When measured during algicide exposure, oyster pediveliger activity declined at concentrations $\geq 10 \%$. In both assays, oyster pediveligers reduced swimming activity and closed their shell valves, thereby isolating their tissue and reducing exposure to the algicide. This is consistent with how juvenile/adult bivalves adjust shell gaping in response to other environmental factors ${ }^{34,47,48}$. However, while adult oysters minimized their shell gape when exposed to high algicide, this had no effect on their clearance rate.

Collectively, lethal and sublethal assays suggest earlier, smaller life stages are more sensitive to this algicide than later, larger stages. Nevertheless, algicide effects were minimal or absent at the algicide concentration required to inhibit dinoflagellate growth $(\mathrm{EC} 50 \approx 1 \% \mathrm{v} / \mathrm{v})^{27}$. It is likely that local algicide application for HAB control and mitigation will require concentrations $>1 \%$ in order to reach this concentration over larger spatial scales. The highest algicide concentration we tested was $40 \%$; high concentrations resulted in a range of effects, but these were highly species and stage dependent. Future modeling work should examine water residence time in potential application areas to assess what field concentrations animals would likely be exposed to, and how long those exposures would last.

More generally, isolated algicidal compounds such as IRI-160AA are promising in their role of controlling harmful dinoflagellate blooms. While there may be risks to metazoans at the site of application where locally high concentrations would be experienced, these effects are limited. Given the substantial negative impacts of HABs across higher trophic levels ${ }^{10,11,47,51,58}$, the risk of direct exposure of metazoans to algicide during control seems tolerable. This should be confirmed in mesocosm studies where dinoflagellates and metazoans can be exposed to algicide simultaneously.

\section{Methods}

Algicide preparation. Four batches of algicide were used for experiments, labeled Batch 3, Batch 4-5-6, Batch 7, and Batch 8, following methods used by Grasso ${ }^{27}$. For each batch, a single colony of Shewanella sp. IRI-160 was transferred from a modified LM medium plate to liquid LM medium for overnight growth, then inoculated into $\mathrm{f} / 2$ with $0.05 \%$ casamino acids and incubated for 10 days at room temperature with bubbling. Bacteria and other compounds greater than $60 \mathrm{kDa}$ in size were filtered out using a HemoFlow HF80S $60 \mathrm{kDa}$ dialysis cartridge (Fresenius Medical Care, Waltham, MA), creating a batch of sterile filtered exudate referred to as IRI-160AA. Samples of the algicide were diluted with ultrapure water, then total nitrogen (TN) was measured with a TOC-V total organic carbon analyzer equipped with a Total Nitrogen Measuring Unit (Shimadzu Corp., Kyoto, Japan). The algicide has approximately $5.02 \mathrm{mg} / \mathrm{L} \mathrm{TN}$. The 24-h EC50 for K. veneficum differed among batches but was always close to $1 \%$ (actual EC50s ranged from $0.93 \%$ in Batch $4-5-6$ to $1.5 \%$ in Batch 3), thus a $1 \%$ concentration of the algicide was included in all invertebrate assays ${ }^{27}$. Animals were also exposed to a media control to ensure mortality was due to the algicide.

Statistical analyses. For all statistics, data were analyzed using Shapiro-Wilk normality tests and BrownForsythe equal variance tests. If they failed either, data were transformed and reanalyzed. If transformed data passed both tests, then analysis proceeded. If neither log or square-root transformed data passed both normality and equal variance tests, then a non-parametric test was run if possible. Specific details on statistical analyses are provided in each section below.

Copepod mortality. Mortality experiments followed established methods for determining acute toxicity in aquatic animals $^{30,31,33,49}$. For $A$. tons $a$ adults, we collected animals in Fall of 2018 after sunset near the mouth of the Broadkill River (Delaware, USA) using a plankton net. Cod ends were diluted and maintained in field collected seawater with ambient food at room temperature $\left(\sim 20^{\circ} \mathrm{C}\right)$ until use in experiments. Adults were filtered out of the bulk collection with a 500- $\mu$ m mesh, then sorted for adult females. We transferred one adult female ( $\mathrm{n}=24$ for $40 \%, 48$ for $30 \%$, and 72 for all other concentrations) into each well of a 12 -well plate containing $5 \mathrm{~mL}$ of test solution; test solutions included a seawater control (0\%); algicide mixtures prepared from Batch 3 of the IRI-160AA in 20 psu, $0.2 \mu \mathrm{m}$-filtered sea water collected from Indian River Inlet, DE, USA (FSW) (1\%, 5\%, 10\%, $13.5 \%, 18 \%, 24 \%, 30 \%$, and $40 \% \mathrm{v} / \mathrm{v})$; and a $24 \%$ media solution as a media control. The plates were incubated at $25^{\circ} \mathrm{C}$ in low-light $\left(\sim 2.37 \times 10^{13}\right.$ photons $\left.\mathrm{cm}^{-2} \mathrm{~s}^{-1}\right)$ on a $14: 10 \mathrm{~h}$ day:night cycle for $48 \mathrm{~h}$. Every $6 \mathrm{~h}$ for the first $24 \mathrm{~h}$, and again at $48 \mathrm{~h}$, we counted the number alive and dead.

For A. tonsa nauplii, adult females and males were placed in two $1 \mathrm{~L}$ beakers at room temperature with a $150-\mu \mathrm{m}$ mesh placed several centimeters off the bottom (to prevent egg cannibalism), a slow bubbler ( $\sim 2$ small 
bubbles $\mathrm{s}^{-1}$ ), and ambient seawater diluted with 20 psu FSW until the water was mostly clear. Adults were allowed to mate in the beaker for approximately $24 \mathrm{~h}$, after which we removed the mesh, thus removing the adults and leaving behind any nauplii and eggs. After another $24 \mathrm{~h}$, the contents of the beakers were poured through a $20-\mu \mathrm{m}$ mesh, and we extracted the nauplii and placed them into experimental treatments $(0 \%$ seawater control, algicide at $1 \%, 5 \%, 10 \%, 13.5 \%, 18 \%, 24 \%$, and $30 \% \mathrm{v} / \mathrm{v}$ concentrations, plus a $24 \%$ media control; $\mathrm{n}=48$ animals for all concentrations) following the procedure outlined above for the adult female copepods. This experiment was conducted three times; the first two mortality experiments used Batch 3 of the IRI-160AA, and the third mortality experiment used Batch 8 .

From the data collected, we generated a Probit mode ${ }^{50}$ and obtained a 24-h LC50. Another approach looks at mortality over several time points in order to generate a time series of survival (e.g., Robineau et al..$^{51}$, Keller et al. ${ }^{52}$ ). This also allows the generation of an LC50 at several time points (e.g., 6, 12, 18, and $24 \mathrm{~h}$ ), which can better inform how a certain animal may survive over time. We used SigmaPlot to generate graphs of survival over time, and R statistical software ${ }^{53}$ and the R package ecotoxicology $y^{54}$ for generating and graphing the Probit model and running a $\chi^{2}$ test to evaluate the model.

Crab mortality. We conducted mortality experiments for the blue crab (Callinectes sapidus) in larval (Z1-stage zoeae) and postlarval (megalopae) stages in a similar manner to mortality experiments with Acartia tonsa. We collected ovigerous female blue crabs during the Summer of 2018 by dip net and drop net at sunset from the Delaware Bay (similar to methods used by Kernehan ${ }^{55}$ ) in Cape Henlopen State Park and maintained them in a recirculating water tray containing filtered ambient seawater $(\sim 30 \mathrm{psu})$ at room temperature. We staged egg masses every few days ${ }^{55}$, and females predicted to hatch within $\sim 3$ days were moved to 7 -gallon buckets in a $25^{\circ} \mathrm{C}$ incubator containing 30 psu sea water and a bubbler. Zoea larvae (Z1-stage) hatched from these females were kept in large finger bowls with 30 psu sea water at room temperature and were fed lab-reared rotifers (Brachionus rotundiformis, Reed Mariculture). These animals became subjects for mortality and sublethal experiments within approximately a day of hatching. Four experiments were conducted; three mortality experiments used Batch 4-5-6 of the IRI-160AA, while the fourth experiment (24 individuals for each concentration) used Batch 7.

Megalopae were collected by plankton net set on rising tides at night during the Summer and Fall of 2018. They were maintained in large finger bowls at room temperature and fed with Artemia nauplii and went into experiments within a few days of collection. Only megalopae in intermolt based on morphology ${ }^{56}$ were used in experiments. Megalopae experiments used Batch 3 of the IRI-160AA.

Both zoeae and megalopae were exposed to $1 \%, 5 \%, 10 \%, 13.5 \%, 18 \%$, and $24 \%$ algicide concentrations, plus a $0 \%$ seawater control and a $24 \%$ media control $(n=84$ animals for the $0 \%$ concentration and 60 for all other concentrations for zoeae, and $n=24$ animals for megalopae for all concentrations). Animals were incubated at $25^{\circ} \mathrm{C}$ under low-light $\left(\sim 2.37 \times 10^{13}\right.$ photons $\left.\mathrm{cm}^{-2} \mathrm{~s}^{-1}\right)$ on a 14:10 light:dark cycle for the duration of experiments. We checked on zoeae and megalopae every $6 \mathrm{~h}$ for $24 \mathrm{~h}$; megalopae were checked at an additional 48 -h time point.

Oyster mortality. Oyster larvae (eyed pediveligers of Crassostrea virginica) were provided by University of Maryland's Horn Point Laboratory. Animals were maintained on a damp coffee filter in a sealed plastic container on ice during transport, then released into room-temperature fingerbowls containing 20 psu water and fed a locally-isolated alga (Storeatula major) at room temperature. Experiments occurred in similar fashion to those conducted on Acartia tonsa and Callinectes sapidus. Larvae were assayed in 12-well plates $(\mathrm{n}=36$ animals for all concentrations). Animals were exposed to $1 \%, 5 \%, 10 \%, 13.5 \%, 18 \%$, and $24 \%$ algicide concentrations, plus a $0 \%$ seawater control, and $24 \%$ media control. Animals were incubated at $25^{\circ} \mathrm{C}$ under a $14: 10$ light:dark cycle for the duration of experiments. Survival was evaluated every $6 \mathrm{~h}$ for $24 \mathrm{~h}$ and again at $48 \mathrm{~h}$. Larvae were additionally examined at the start of the experiment and at the 24 - and 48-h time points for an activity assay. These experiments used Batch 3 of the IRI-160AA.

Wild-type adult C. virginica were collected from the Delaware Bay near the University of Delaware Lewes Campus, while Haskins-disease-resistant strain individuals were collected from aquaculture cages maintained by the Delaware Center for the Inland Bays. On the first day, individuals were cleaned with a wire brush, and divided into two buckets containing approximately $10 \mathrm{~L}$ of 20 psu seawater and were fed Isochrysis galbana $\left(\sim 100,000\right.$ cells $\left.\mathrm{L}^{-1}\right)$. On the second day the water was changed and they were again fed. On the third day, water was changed and animals were not fed. On the fourth day, individuals were removed from the buckets, dried with a paper towel, labeled with permanent marker, and placed in pairs into forty-one $1 \mathrm{~L}$ plastic containers containing $1 \mathrm{~L}$ of various algicide solutions: $0 \%, 1 \%, 5 \%, 10 \%, 13.5 \%, 18 \%$, and $24 \%(\mathrm{n}=28$ for $0 \%, 22$ for $1 \%$ and $18 \%$, and 20 for all other concentrations). Individuals were checked every $6 \mathrm{~h}$ for $24 \mathrm{~h}$ and assessed if they were alive or dead. Closed individuals were assumed to be alive. If open individuals were observed, we gently tapped on the container to see if the individual shut its shell; animals that responded to this stimulus were marked as alive. Only animals that did not respond to repeated stimuli were scored as dead. Proportion surviving was compared across algicide concentration and strain. These experiments all used Batch 8 of the IRI-160AA.

Copepod sub-lethality. Respiration. We conducted respiration experiments on A. tonsa adult females and young nauplii in a 24 -well microplate respirometer (Loligo Systems). First, we sorted animals into fingerbowls containing $100 \mathrm{~mL}$ of their respective algicide concentrations. After $24 \mathrm{~h}$ of algicide exposure, we removed animals via pipette and put one animal into each well of the respirometer plate $(200 \mu \mathrm{L}$ wells for adult females and $80 \mu \mathrm{L}$ for nauplii) filled with $0.2 \mu \mathrm{m}$ filtered FSW, then sealed the plate with Parafilm and a weight. Each experiment also had 4 to 6 wells with only FSW to calculate background oxygen consumption. The experiment occurred in darkness within a $25^{\circ} \mathrm{C}$ incubator at night and lasted several hours $(\mathrm{n}=26-39$ animals for adult 
females, 11-18 for nauplii). Oxygen concentrations in each well were recorded every minute. At the end of the experiment, respiration rates were calculated in $\mathrm{R}$ statistical software using the resp $R$ package ${ }^{57}$ over a period of time when the animals were still in independent respiration, and a one-way ANOVA on ranks in SigmaPlot (Systat Software, San Jose, CA) compared treatments. Experiments with adult females used Batch 3 of IRI-160AA, while nauplii experiments used Batch 8 .

Activity. Experiments determining effects on swimming activity utilized Locomotor Activity Monitors (LAMs; TriKinetics). Three beams of infrared light cross a $3 \mathrm{~mL}$ test tube containing an animal and register when the animal crosses the beams. We sorted batches of adult female $A$. tonsa into fingerbowls containing different algicide treatments. Animals were incubated at $25^{\circ} \mathrm{C}$ in low-light conditions $\left(\sim 2.37 \times 10^{13}\right.$ photons cm $\left.\mathrm{c} \mathrm{s}^{-1}\right)$ for $24 \mathrm{~h}$ on a 11:13-h light:dark cycle. Animals were pipetted into plastic test tubes (one animal per tube) containing $\sim 3 \mathrm{~mL}$ of FSW, which then went into the LAMs ( $\mathrm{n}=21-36$ animals). The experiment lasted $24 \mathrm{~h}$ with beam breaks summed at one-minute intervals, allowing the data to be analyzed wholly for the 24-h period as well as across different light phases to account for light:dark mediated activity rhythms. Experiments started in the afternoon and ran overnight, creating an initial light phase (L1), a dark phase (D), and a second light phase (L2). Comparing treatments across the entire time period was done using a one-way ANOVA on ranks, while analyzing the data based on the different light phases was performed via a one-way repeated-measures ANOVA. Additionally, at the end of the LAM activity experiments we collected the individuals and noted mortality. This data was analyzed via a one-way ANOVA on ranks. Copepod activity experiments used Batch 3 of the IRI-160AA. Nauplii were too small to generate a reliable signal in the LAMs and were not used in these experiments.

Crab sub-lethality. Respiration. Respiration experiments followed methods described for A. tonsa above and involved zoeae and megalopae. A one-way ANOVA on ranks was calculated using the data for each life stage. The first four zoeae experiments used Batch 4-5-6 of IRI-160AA, while the last two experiments used Batch 7. Megalopae experiments all used Batch 3.

Activity. Activity level experiments followed methods described for A. tonsa above and involved zoeae and megalopae. The 24-h data were analyzed using a one-way ANOVA on square root transformed data for zoeae, and a one-way ANOVA on ranks for megalopae. The data broken down by light phase were analyzed via one-way repeated measures ANOVA on log-transformed data for both zoeae and megalopae. These experiments all used Batch 3 of IRI-160AA.

At the end of experiments we collected the individuals and noted mortality. This data was analyzed via a one-way ANOVA for zoeae and a one-way ANOVA on ranks for the megalopae.

Metamorphosis. We sorted megalopae into finger bowls containing $100 \mathrm{~mL}$ of filtered estuary water with different concentrations of the IRI-160AA algicide $(0 \%, 1 \%$, and $17 \% \mathrm{v} / \mathrm{v})$. After 24 -h of exposure, we sorted animals into 12-well plates containing FSW ( $\mathrm{n}=60$ individuals for each treatment). Water was changed daily, and animals were fed freshly hatched Artemia daily. Every $12 \mathrm{~h}$, we counted how many megalopae had molted into first crabs until most had metamorphosed (5.5 days) and used a Kaplan-Meier Survival Analysis with a GehanBreslow test to determine if there was a difference in time to metamorphosis (TTM) across treatments. These experiments used Batch 3 of the IRI-160AA.

Abdomen Pumping and Grooming. Crabs with egg masses were collected from the Delaware Bay near Lewes, $\mathrm{DE}$ and separated into numbered baskets and maintained in a flow-through sea water table. They were fed thawed squid (Loligo opalescens) every day, and eggs were photographed every two to three days under a dissecting scope until they reached $\sim 6$ days until hatching (i.e., late-stage sensu Tankersley et al. ${ }^{36}$. Homogenized egg water (seawater plus homogenized eggs, designated $\mathrm{SW}+\mathrm{HE}, \sim 20$ eggs $\mathrm{mL}^{-1}$ ) was utilized to induce pumping and grooming behavior and made according to Tankersley et al. ${ }^{36}$.

Ovigerous females were exposed to several sub-lethal concentrations of algicide combined with the homogenized egg solution and monitored for pumping and grooming behavior. Test solutions were diluted to $1.5 \mathrm{~L}$ with filtered 30 psu seawater, and $3.75 \mathrm{~mL}$ aliquot of a pre-prepared homogenized egg solution was added to achieve a final concentration of $\sim 20$ eggs/mL. These experiments used Batch 4-5-6, Batch 7, and Batch 3 of the IRI-160AA.

Between three and six crabs were tested at a time, and all crabs were staged the day of the experiment to verify that their eggs were no more than six days from hatching. All experiments were performed under dim red light to reduce disturbance. Each crab was tested in every treatment. A crab was placed into a translucent container $(20.1 \times 16.5 \times 11.4 \mathrm{~cm})$ with a given treatment condition and acclimated for $2.5 \mathrm{~min}$. Then, for the following $2.5 \mathrm{~min}$, the number of times the crab pumped its abdomen was recorded. Immediately following the end of the first crab's measurement period, another crab was placed into the same treatment to begin its acclimation period. Each crab was returned to a flowing water table between treatments and remained there for at least twenty minutes before beginning the acclimation period of its next treatment. The treatment series began and ended with 30 psu seawater (SW), and proceeded through an increasing gradient of $0,7,11$, and 17\% IRI-160AA in SW + HE.

Each measurement period of the pumping experiments was filmed. The videos were reviewed later, and the time the crabs spent grooming their egg masses was recorded.

A $\chi^{2}$ test was performed for the 24 crabs tested to assess if the proportion of crabs performing the behaviors differed among treatments. A one-way repeated-measures ANOVA (Friedman Repeated Measures Analysis of Variance on Ranks) was used to assess trends in the number of pumps and the time spent grooming. Only crabs that performed the behavior were included in each analysis. 
Oyster sub-lethality. Respiration. Respiration on oyster pediveligers following methods described for $A$. tonsa nauplii above. Two individuals were placed in each $80 \mu \mathrm{l}$ well, with rates calculated per individual. Data were analyzed via a one-way ANOVA on Ranks. These experiments all used Batch 3 of IRI-160AA.

Activity. Activity experiments on pediveliger larvae were conducted in LAMs and followed similar methods to Acartia tonsa and Callinectes sapidus. The 24-h data was tested via a one-way ANOVA on ranks, while the data broken down by light phase was analyzed via a one-way repeated measures ANOVA. These experiments used Batch 3 of IRI-160AA.

An additional analysis of pediveliger activity occurred during the mortality experiment by ranking how active each animal appeared to be on a scale of 1 (High Activity, HA, animal was actively swimming), 2 (Medium Activity, MA, animal had its velum extended and cilia active, sometimes scooting across the bottom), 3 (Low Activity, LA, animal was enclosed in its shell but viscera moved when the shell was touched), and 4 (Dead/No Activity, D, animal was completely unresponsive even to repeated stimulation). Ranking occurred at the start of the experiment (where all animals scored as HA), at the 24 -h mark, and at the 48 -h mark. This assessment was analyzed via a $\chi^{2}$ test for both the $24-\mathrm{h}$ and $48-\mathrm{h}$ data sets. At the end of the LAM experiments, animals were analyzed in the same manner.

Activity experiments on the wild-type adult $C$. virginica occurred during the mortality experiments. At each 6-h time point, animals in the containers $(0 \%, 1 \%, 5 \%, 10 \%, 13.5 \%, 18 \%$, and $24 \% \mathrm{v} / \mathrm{v}$ IRI-160AA treatments) were scored as either Open $(\mathrm{O})$ or Closed $(\mathrm{C})$, and analyzed via a two-way repeated measures ANOVA on the proportion of animals that opened at each time point in each concentration.

Feeding. Feeding experiments occurred only on adult C. virginica. Animals and containers from the mortality experiments were rinsed to remove algicide residue, then filled with $1 \mathrm{~L}$ of 20 psu seawater and Isochrysis galbana at $\sim 100,000$ cells $\mathrm{L}^{-1}$, and one animal from each container was returned to it. Five milliliters from each container were removed immediately and in vivo chlorophyll $a$ florescence was measured using a fluorometer (Turner Systems). Air stones were added to the containers to keep the algae in suspension, and lids were added to prevent liquid from bubbling out. After $6 \mathrm{~h}$, another fluorescence reading was taken. Animals were given another $6 \mathrm{~h}$ to feed, and a final fluorescence reading was taken at the 12 -h time point. Clearance rates (CR) were calculated according to Thessen et al. ${ }^{58}$ from time zero to six hours (initial rate, $0-6$ ), and from six to twelve hours (end rate, 6-12), and compared across time ranges and treatments and strains using a three-way ANOVA.

\section{Data availability}

The data generated and analyzed during the current study are available from the corresponding author upon reasonable request.

Received: 4 May 2020; Accepted: 9 December 2020

Published online: 12 January 2021

\section{References}

1. Anderson, C. R., K. G. Sellner \& D. M. Anderson. Bloom prevention and control. In Harmful algal blooms (HABs) and desalination: A guide to impacts, monitoring and management (ed. Anderson, D.M., Boerlage, S.F.E. \& Dixon, M.B.). 205-222 (IOC Manuals and Guides 78, 2017).

2. Watson, S. B. et al. The re-eutrophication of Lake Erie: Harmful algal blooms and hypoxia. Harmful Algae 56, 44-66 (2016).

3. Wells, M. L. et al. Harmful algal blooms and climate change: Learning from the past and present to forecast the future. Harmful Algae 49, 68-93 (2015).

4. Paerl, H. W. et al. Mitigating cyanobacterial harmful algal blooms in aquatic ecosystems impacted by climate change and anthropogenic nutrients. Harmful Algae 54, 213-222 (2016).

5. Anderson, D. M. Prevention, control and mitigation of harmful algal blooms: Multiple approaches to HAB management in Harmful Algae Management and Mitigation (ed. Hall, S., Etheridge, S., Anderson, D., Kleindinst, J., Zhu, M. \& Zou, Y.). 123 - 130 (AsiaPacific Economic Coooperation (Singapore), 2004). APEC Publication \#204-MR-04.2

6. University of Delaware Citizen Monitoring Program. Harmful algae report: all data between 7/6/2018 and 7/19/2018. University of Delaware SGMAS (2018).

7. Place, A. R. et al. Karlodinium veneficum-The little dinoflagellate with a big bite. Harmful Algae 14, 179-195 (2012).

8. Van Wagoner, R. M. et al. Isolation and characterization of karlotoxin 1, a new amphipathic toxin from Karlodinium veneficum. Tetrahedron Lett. 49, 6457-6461 (2008).

9. Van Wagoner, R. M. et al. Structure and relative potency of several karlotoxins from Karlodinium veneficum. J. Nat. Prod. 73, 1360-1365 (2010).

10. Stoecker, D. K., Adolf, J. E., Place, A. R., Gilbert, P. M. \& Meritt, D. W. Effects of the dinoflagellates Karlodinium veneficum and Prorocentrum minimum on early life history stages of the eastern oyster (Crassostrea virginica). Mar. Biol. 154, 81-90 (2008).

11. Delgado, M. \& Alcaraz, M. Interactions between red tide microalgae and herbivorous zooplankton: The noxious effects of Gyrodinium corsicum (Dinophyceae) on Acartia grani (Copepoda: Calanoida). J. Plankton Res. 21, 2361-2371 (1999).

12. Yu, Z., Song, X., Cao, X. \& Liu, Y. Mitigation of harmful algal blooms using modified clays: Theory, mechanisms, and applications. Harmful Algae 69, 48-64 (2017).

13. Jeong, J.-H., Jin, H.-J., Sohn, C. H., Suh, K.-H. \& Hong, Y.-K. Algicidal activity of the seaweed Corallina pilulifera against red tide microalgae. J. Appl. Phycol. 12, 37-43 (2000).

14. Li, Z. et al. A freshwater bacterial strain, Shewanella sp. Lzh-2, isolated from Lake Taihu and its two algicidal active substances, hexahydropyrrolo[1,2-a]pyrazine-1,4-dione and 2,3-indolinedione. Appl. Microbiol. Biot. 98, 4737-4748 (2014).

15. Baker, K. H. \& Herson, D. S. Interactions between the diatom Thallasiosira pseudonanna and an associated Pseudomonad in a mariculture system. Appl. Environ. Microb. 35, 791-796 (1978).

16. Cole, J. J. Interactions between bacteria and algae in aquatic ecosystems. Annu. Rev. Ecol. Syst. 13, 291-314 (1982).

17. Lovejoy, C., Bowman, J. P. \& Hallegraeff, G. M. Algicidal effects of a novel marine Pseudoalteromonas isolate (Class Proteobacteria, Gamma Subdivision) on harmful algal bloom species of the genera Chattonella, Gyrodinium, and Heterosigma. Appl. Environ. Microb. 64, 2806-2813 (1998). 
18. Skerratt, J. H., Bowman, J. P., Hallegraeff, G., James, S. \& Nichols, P. D. Algicidal bacteria associated with blooms of a toxic dinoflagellate in a temperate Australian estuary. Mar. Ecol. Prog. Ser. 244, 1-15 (2002).

19. Mayali, X. \& Azam, F. Algicidal bacteria in the sea and their impact on algal blooms. J. Eukaryot. Microbiol. 51, 139-144 (2004).

20. Kidwell, D. Mitigation of harmful algal blooms: The way forward. PICES Press 23, 22-24 (2015).

21. NOAA (National Oceanic and Atmospheric Association). Programmatic Environmental Assessment for the Prevention, Control, and Mitigation of Harmful Algal Blooms Program. www.coastalscience.noaa.gov (2015).

22. National Sea Grant College Program (U.S.). Prevention, Control, and Mitigation of Harmful Algal Blooms: A Research Plan (NOAA, Washington, 2001).

23. Hare, C. E. et al. A bacterium that inhibits the growth of Pfiesteria piscicida and other dinoflagellates. Harmful Algae 4, 221-234 (2005).

24. Pokrzywinski, K. L., Place, A. R., Warner, M. E. \& Coyne, K. J. Investigation of the algicidal exudate produced by Shewanella sp. IRI-160 and its effects on dinoflagellates. Harmful Algae 19, 23-29 (2012).

25. Pokrzywinski, K. L., Tilney, C. L., Warner, M. E. \& Coyne, K. J. Cell cycle arrest and biochemical changes accompanying cell death in harmful dinoflagellates following exposure to bacterial algicide IRI-160. Sci. Rep. 7, 45102 (2017).

26. Tilney, C. L., Pokrzywinski, K. L., Coyne, K. J. \& Warner, M. E. Effects of a bacterial algicide, IRI-160AA, on dinoflagellates and the microbial community in microcosm experiments. Harmful Algae 39, 210-222 (2014).

27. Grasso, C.R. Effects of the bacterial algicide IRI-160AA on the microbial community composition of the Delaware Inland Bays. Unpublished Master's thesis, The University of Delaware, Lewes, DE (2018).

28. Ternon, E., Wang, Y. \& Coyne, K. J. Small polar molecules: A challenge in marine chemical ecology. Molecules 24, 1-17 (2019).

29. Abbott, W. S. A method of computing the effectiveness of an insecticide. J. Am. Mosquito Contr. 3, 302-303 (1987).

30. Environmental Protection Agency. Methods for measuring the acute toxicity of effluents and receiving waters to freshwater and marine organisms. EPA Publication 821-R-02-012 (2002).

31. ASTM International. Standard guide for conducting acute toxicity tests on test materials with fishes, macroinvertebrates, and amphibians. ASTM Publication E729-96. https://doi.org/10.1520/E0729-96R14 (2014).

32. Ratcliffe, D. A. Decrease in eggshell weight in certain birds of prey. Nature 215, 208-210 (1967).

33. Cohen, J. H., McCormick, L. R. \& Burkhardt, S. M. Effects of dispersant and oil on survival and swimming activity in a marine copepod. Bull. Environ. Contam. Tox. 92, 381-387 (2014).

34. Porter, E. T. \& Breitburg, D. L. Eastern oyster, Crassostrea virginica, valve gape behavior under diel-cycling hypoxia. Mar. Biol. 163, $163-218(2016)$

35. Forward, R. B. Jr., Tankersley, R. A., Blondel, D. \& Rittschof, D. Metamorphosis of the blue crab Callinectes sapidus: Effects of humic acids and ammonium. Mar. Ecol. Prog. Ser. 157, 277-286 (1997).

36. Tankersley, R. A., Bullock, T. M., Forward, R. B. Jr. \& Rittschof, D. Larval release behaviors in the blue crab Callinectes sapidus: Role of chemical cues. J. Exp. Mar. Biol. Ecol. 273, 1-14 (2002).

37. Yeghissian, T. G. Multi-decadal, seasonal, and spatial variation of calanoid copepod body size in Delaware Bay. Unpublished Master's thesis, The University of Delaware, Lewes, DE (2018).

38. Herman, S. S., Hargreaves, B. R., Lutz, R. A., Fritz, L. W. \& Epifanio, C. E. Zooplankton and parabenthos. In The Delaware Estuary: Research as Background for Estuarine Management and Development (ed. Sharp, J. H.) 157-168 (University of Delaware Sea Grant College Program, Lewes, 1984).

39. Petrone, C. J. Copepod diversity and density at the mouth of Delaware Bay. BIOS 72, 92-99 (2001).

40. Wickline, A. Seasonal and historical mesozooplankton dynamics in Delaware Bay: An application and optimization of the ZooScan optical imaging tool. Unpublished Master's thesis, The University of Delaware, Lewes, DE (2016).

41. Hill, J., Fowler, D. L. \& Van Den Avyle, M. J. Species profiles: Life histories and environmental requirements of coastal fishes and invertebrates (Mid-Atlantic) -Blue crab. U.S. Fish Wildl. Serv. Biol. Rep. 82, 18 pp (1989).

42. Stanley, J. G. \& Sellers, M. A. Species profiles: Life histories and environmental requirements of coastal fishes and invertebrates (Mid-Atlantic)-American oyster. U.S. Fish Wildl. Serv. Biol. Rep. 82, 25 pp (1986).

43. Bellas, J., Beiras, R., Marino-Balsa, J. C. \& Fernandez, N. Toxicity of organic compounds to marine invertebrate embryos and larvae: A comparison between the sea urchin embryogenesis bioassay and alternative test species. Ecotoxicology 14, 337-352 (2005).

44. Osterberg, J. S., Darnell, K. M., Blickley, T. M., Romano, J. A. \& Rittschof, D. Acute toxicity and sub-lethal effects of common pesticides in post-larval and juvenile blue crabs, Callinectes sapidus. J. Exp. Mar. Biol. Ecol. 424-425, 5-14 (2012).

45. Ratte, H. T. Bioaccumulaiton and toxicity of silver compounds: A review. Environ. Toxicol. Chem. 18, 89-108 (1999).

46. Epifanio, C. E. \& Cohen, J. H. Behavioral adaptations in larvae of brachyuran crabs: A review. J. Exp. Mar. Biol. Ecol. 482, 85-105 (2016).

47. Tran, D., Haberkorn, H., Soudant, P., Ciret, P. \& Massabuau, J.-C. Behavioral responses of Crassostrea gigas exposed to the harmful algae Alexandrium minutum. Aquaculture 298, 338-345 (2010).

48. Higgins, P. J. Effects of food availability on the valve movements and feeding behavior of juvenile Crassostrea virginica (Gmelin). I. Valve movements and periodic activity. J. Exp. Mar. Biol. Ecol. 45, 229-244 (1980).

49. Sebaugh, J. L. Guidelines for accurate EC50/IC50 estimation. Pharm. Stat. 10, 128-134 (2011).

50. Bliss, C. I. The calculation of the dosage-mortality curve. Ann. Appl. Biol. 22, 134-167 (1935).

51. Robineau, B., Gagne, J. A., Fortier, L. \& Cembella, A. D. Potential impact of a toxic dinoflagellate (Alexandrium excavatum) bloom on the survival of fish and crustacean larvae. Mar. Biol. 108, 293-301 (1991).

52. Keller, A. A., Garner, K., Miller, R. J. \& Lenihan, H. S. Toxicity of nano-zero valent iron to freshwater and marine organisms. PLoS ONE 7, e43983. https://doi.org/10.1371/journal.pone.0043983 (2012).

53. R Core Team. R: A language and environment for statistical computing. Vienna, Austria. https://www.R-project.org/ (2017).

54. Gama, J. Ecotoxicology: Methods for ecotoxicology. R package version 1.0.1. https://CRAN.R-project.org/package=ecotoxicology (2015).

55. Kernehan, C.D. Determination of the fine scale, temporal pattern of larval release by female blue crabs and application of the information to mathematical models of larval dispersal and recruitment. Unpublished Master's thesis, The University of Delaware, Lewes, DE (2006).

56. Wolcott, D. L. \& De Vries, M. C. Offshore megalopae of Callinectes sapidus: Depth of collection, molt stage and response to estuarine cues. Mar. Ecol. Prog. Ser. 109, 157-163 (1994).

57. Harianto, J. \& Carey, N. respR: Analyse, convert, and automate respirometry-related data. R package version 0.0.5. https://githu b.com/januarharianto/respr

58. Thessen, A. E., Soniat, T. M., Dortch, Q. \& Doucette, G. J. Crassostrea virginica grazing on toxic and non-toxic diatoms. Toxicon 55, 570-579 (2009).

\section{Acknowledgements}

The authors thank Deepak Nanjappa for his work in refining the algicide production process. We thank University of Maryland's Horn Point Lab for providing oyster larvae, and the Delaware Center for the Inland Bays for the Haskins disease-resistant strain oysters. This project was funded by the NOAA PCMHAB program (Grant \# 
NA15NOS4780176) to K.C., M.W., and J.C., contribution number PCM58. This manuscript is based on parts of the thesis "Effects of a Bacteria-Produced Algicide on Non-Target Marine Animal Species" by V.S.

\section{Author contributions}

J.C., K.C., M.W. conceived the research. J.C., K.C., M.D. and V.S. designed experiments and procedures. V.S. and M.D. performed experiments, V.S. and J.C wrote the manuscript. All authors reviewed and edited the manuscript.

\section{Competing interests}

The authors declare no competing interests.

\section{Additional information}

Supplementary Information The online version contains supplementary material available at https://doi. org/10.1038/s41598-020-79814-w.

Correspondence and requests for materials should be addressed to J.H.C.

Reprints and permissions information is available at www.nature.com/reprints.

Publisher's note Springer Nature remains neutral with regard to jurisdictional claims in published maps and institutional affiliations.

Open Access This article is licensed under a Creative Commons Attribution 4.0 International License, which permits use, sharing, adaptation, distribution and reproduction in any medium or format, as long as you give appropriate credit to the original author(s) and the source, provide a link to the Creative Commons licence, and indicate if changes were made. The images or other third party material in this article are included in the article's Creative Commons licence, unless indicated otherwise in a credit line to the material. If material is not included in the article's Creative Commons licence and your intended use is not permitted by statutory regulation or exceeds the permitted use, you will need to obtain permission directly from the copyright holder. To view a copy of this licence, visit http://creativecommons.org/licenses/by/4.0/.

(C) The Author(s) 2021 